\title{
Automatic Monitoring System of the Sevastopol Black Sea Region Marine Environment
}

\author{
A.L. Kholod, Yu.B. Ratner, N.L. Mamchur, M.V. Ivanchik, \\ A.M. Ivanchik \\ Marine Hydrophysical Institute, Russian Academy of Sciences, Sevastopol, \\ Russian Federation \\ e-mail: antonholod@mail.ru,natasha3658@mail.ru
}

\begin{abstract}
Operational monitoring system is developed to automatize the process of diagnosis and forecast of hydrological fields of marine environment in the Sevastopol Black Sea region based on the local hydrodynamical model POM. The initial and boundary conditions for the local model are set from the basin model of the Black Sea dynamics. The data obtained by SKIRON Regional Forecast Center of Athens University is applied as the atmospheric effect. For the parameterization of vertical mixing in local circulation model POM turbulence model based on turbulence hypotheses of Rott - Kolmogorov and generalized by Mellor and Yamada in the case of a stratified flow is included. The model takes into consideration the penetration of the short-wave solar radiation into the water column. System automation is implemented using the CalcMan software package which is an own development of Marine Hydrophysical Institute. The output fields are accessible in the NetCDF format with horizontal spatial resolution constituting $1 \mathrm{~km}$, vertical resolution - 18 irregular levels from 2.5 to $1000 \mathrm{~m}$ and time resolution $-3 \mathrm{hr}$. The system provides a possibility of daily updating the forecast data.

Based on the THREDDS server, the specialized visualization subsystem is installed and configured to visualize and disseminate simulations results. Its user-friendly interface allows a server-side analysis of all the forecasted fields, permits to construct horizontal and vertical sections, vertical profiles and time series, to create animated pictures without downloading the data to a client's side. OPENDAP and NetcdfSubset interfaces are used for disseminating data in a digital form.
\end{abstract}

Keywords: automatic system, information technology, simulation, monitoring, hydrodynamical model, temperature, salinity, current velocity, sea level, diagnosis, forecast, validation, visualization, THREDDS-server.

DOI: $10.22449 / 1573-160 X-2015-4-66-77$

(C) 2015, A.L. Kholod, Yu.B. Ratner, N.L. Mamchur, M.V. Ivanchik, A.M. Ivanchik

(C) 2015, Physical Oceanography

\section{Introduction}

Operational marine forecasts for the Black Sea coastal region require the results with high spatial resolution $\sim 1 \mathrm{~km}$. At present construction of circulation models for the whole Black Sea area with such a resolution and the very simulations take too much time that does not satisfy the demands made to efficiency of the models. Therefore, to make forecasts in the coastal regions, the regional (local) models of circulation are developed and applied. At that on rather small bounded sea area of interest one can already use sufficiently small spatial steps providing acceptable time of simulations. Such simulations imply taking into account influence of the open sea adjoining the region under investigation upon the dynamics of its sea currents and other fields. For this purpose it is necessary to preset the edge conditions on the opened liquid boundaries of the region under examination.

For presetting boundary conditions, the simulation results for the whole Black Sea basin (but with lower spatial resolution $5 \mathrm{~km}$ ) obtained due to the basin model of the Marine hydrophysical institute are attracted and the technology of one-way 
nested grid model is used [1 - 7]. According to this approach the information is transferred only from the global model to the regional one and the solution obtained from the model with high resolution in no way influence the solution in the area with a coarse grid. Choice of such an approach is conditioned, first, by the fact that simulations by the regional model are assumed to be conducted for rather short periods (not more than 10 days). Besides, the global model simulates the fields on the whole water area including that of the region model; at that the data of remote and direct measurements are continuously assimilated. Second, the accepted approach permits to carry out simulations for the whole water area and for the chosen region independently of one another that provides saving of time at using the system of hydrophysical fields' nowcasting and forecasting in the operational mode. Exactly such a scheme constituted a basis for constructing the system of local marine forecasts.

At present the monitoring system intended for realizing local marine forecasts in the region including the Black Sea north-western shelf and the water area adjoining the Crimea western and southern coasts functions in the Marine hydrophysical institute [8]. Besides, based on the data resulted from the basin model of the Black Sea and using the specialized system, the arrays of boundary and initial conditions for the coastal regions of Georgia, Bulgaria, Romania and the Russia Caucasian coast are being formed. Experimental tests of these systems permitted to confirm utility and adequateness of the principles constituting a basis of their construction. At the same time in course of experimental testing of the local sea forecast system, some drawbacks were revealed: unacceptable long time spent for making forecasts for the chosen region, insufficient time frequency of outputting the forecast results and absence of suitable and functional subsystem of data visualization and dissemination. All the drawbacks were removed in course of development of the noted above system of marine environment nowcasting and forecasting in the Sevastopol region of the Black Sea.

\section{Brief information on the hydrodynamic model used for local marine forecasts}

The Princeton Ocean Model (POM) which proved to be good in creating prognostic systems is used as a pattern for carrying out local forecasts for the Sevastopol region of the Black Sea. The local model POM with high resolution [9] is a modification of the Australian version [10] of a three-dimensional numerical hydrodynamic model of ocean circulation of the Princeton University [11] adapted to the Black Sea conditions. POM is based on the total system of hydrodynamics equations with approximations of Boissinesque and hydrostatics, and s-transfor-mation of the vertical coordinate. The $\sigma$-coordinate system used in the model implies normalizing the vertical coordinate on the ocean depth. The external effects include heat fluxes, tension of wind friction, evaporation and precipitation resulted from the atmospheric forecasts' data.

The models in $\sigma$-coordinates possess the following advantages: smoothed representation of bottom topography which, in addition, provides a possibility to describe more exactly physics of the processes in the near-bottom boundary layer, adequate spatial resolution of the surface and near-bottom layers [12]; at that the only undesirable element at good resolution of the surface layer in the deep-sea part of the simulated area, is a somewhat surplus resolution of this layer in the shalPHYSICAL OCEANOGRAPHY NO. 4 (2015) 
low-water parts [1]. Besides, the models in $\sigma$-coordinates permit to use much more lower values of horizontal viscosity and diffusion [2] than the models in z-coordinates, and the errors in the z-coordinate models conditioned by viscosity, in the shallow regions can considerably exceed the errors of pressure gradients in the $\sigma$-coordinate models for the shallow-water areas.

To parametrize vertical mixing, the turbulence model based on the Rott Kolmogorov hypotheses on turbulence and generalized by Mellor and Yamada [3] for the case of a stratified flow, is installed to the circulation model POM. Penetration of short-wave solar radiation to the water thickness which is preset according to $[4,5]$ is taken into account in this model.

The purpose of the present paper is to describe both the results of development of the automatic system for forecasting the marine environment conditions in the Sevastopol region of the Black Sea and the subsystem of its visualization. After the required experimental data are accumulated the model will be tuned and the simulation results will be validated.

\section{Administration of the computing process for realizing marine forecasts of the Sevastopol coastal region in the Black sea}

Algorithm of a forecast realization. At the first stage the forecast is executed using the Black Sea global (basin) model with a spatial resolution $5 \mathrm{~km}$. Then a simulation by the local model is done for forecasting the situation in the Sevastopol region. At that the data for simulating the parameters on the interface taken from the corresponding grid knots of the basin model, and the data on the values of wind friction tension, heat fluxes, precipitation and evaporation intensity in the nodes located on the sea surface are transmitted to the local model with the preset discreteness. These data are interpolated in the corresponding nodes of the small-scale grid on the interface and on the sea surface. The interpolated velocity values on the lateral liquid boundaries are corrected so that the total amount of liquid passing through the lateral boundary should exactly equal the liquid amount calculated due to the current velocity values in the basin model. For each calculation moment the boundary values are obtained by linear interpolation using the time neighboring values.

Local marine forecast for the Sevastopol region is executed daily for 3 days; the forecast results are delivered at standard meteorological terms 00:00, 03:00, 06:00, 09:00, 12:00, 15:00, 18:00, 21:00 UTC (universal coordinated time). The forecasted parameters are the following: temperature and salinity of seawater, horizontal components of current velocity and dynamic level of the sea surface.

Input data. All the required input data used in the local model during forecasting are obtained just after a current cycle of the basin system functioning is over. The input data include the following arrays:

- temperature and salinity of seawater, horizontal component of current velocities and the sea surface level for presetting initial conditions;

- meteorological information on the fluxes of momentum, heat and evaporation-precipitation for presetting boundary conditions on the sea surface;

- temperature and salinity of seawater, component of current velocities and sea surface level for presetting boundary conditions on the liquid open boundary of the region. 
Output data. The results of forecasts for the Sevastopol region are recorded in the files of the Network Common Data Form (NetCDF) format which was developed within the framework of the program Unidata by the University Corporation for Atmospheric Research (UCAR). It is one of the most widespread international formats for exchanging hydrometeorological and oceanographic data. Its advantages are the following: possibility to unite the records of absolutely different types and structures in one file, trend towards high data level, mobility guaranteed by the format and by the supporting instruments, ensuring of rapid input/output, effective storage on various devices and, finally, extension ability. Choice of this format permits to visualize forecasts and transfer them to users through application of a wide set of high-quality foreign and domestic software distributed free by the licenses of the General of Public License (GPL) type.

Realization of a current forecasting cycle results in obtaining the data amount that corresponds to a few diagnostic and prognostic days. The information related to one day is recorded in separate NetCDF-files and contains four-dimensional instantaneous fields of temperature, salinity, zonal and meridian velocity, and also the three-dimensional sea level instantaneous field. Correspondence between the variables and their names in the NetCDF-file is represented in the table.

Correspondence between the variables and the names in the NetCDF-file

\begin{tabular}{l|l}
\hline Variable & Variable name in NetCDF-file \\
\hline Sea level, $\mathrm{m}$ & sea_surface_height_above_sea_level \\
Temperature, $\mathrm{K}$ & sea_water_temperature \\
Salinity, \%o & sea_water_salinity \\
U-component of current, $\mathrm{m} / \mathrm{sec}$ & eastward_sea_water_velocity \\
V-component of current, $\mathrm{m} / \mathrm{sec}$ & northward_sea_water_velocity \\
\hline
\end{tabular}

SEVREM_ANALYSIS_FORECAST_PHYS_010 product is calculated by 18 vertical levels: $2.5,10,20,30,50,75,100,125,150,175,200,250,300,400,500$, 600,700 and $1000 \mathrm{~m}$. Time coverage is the following: 3 days of adaptation and 3 days of forecasting since 00:00 UTC. Prediction and adaptation include instantaneous fields at 00:00, 03:00, 06:00, 09:00, 12:00, 15:00, 18:00 and 21:00 UTC.

\section{Description of the system for automatic marine environment monitoring of the Sevastopol Black Sea region}

The system of nowcasting and forecasting the state of marine environment in the Sevastopol region of the Black Sea runs completely in an automatic mode. The system functioning was automated by means of the CalcMan software package [13]. The system toolbox allows tuning which includes selection of the input data source, change of duration of data adaptation and the model forecast periods, change in configuration of archiving the system output data in the local file archives and in the FTP-server.

The structure of the computing process control system of the local hydrological forecast for the region under study is shown in Fig. 1 as a snapshot of the CMNavigator software of the CalcMan software package [13]. 
The system (indicated in the Fig. 1 as 03_SevREM) includes the task Se$\nu R E M \_M a n a g e r . t s 6$ (the program written in an interpreted language CalcManPack [14]) and 8 subsystems as its members:

- 01_Planning is planning of a current cycle of simulations;

- 02_Input is preparation of the model input data;

-03_Forecasting is the model simulation;

- 04_Archiving is archiving of the model output data in $\sigma$-coordinates in the local file archive;

- 05_ProductPrep is preparation of the NetCDF-files of the system output product, their archiving in the local file archive and on the FTP-server;

- 06_Uploading is preparation of the array of the product files for uploading to the THREDDS-server (Thematic Realtime Environmental Distributed Data Services), data queuing and uploading to the THREDDS-server by the output subsystem (80_Output);

- 07_CalcTermination is completion of a current cycle of simulations;

- 80_Output is queue management of data output on the THREDDS-server.

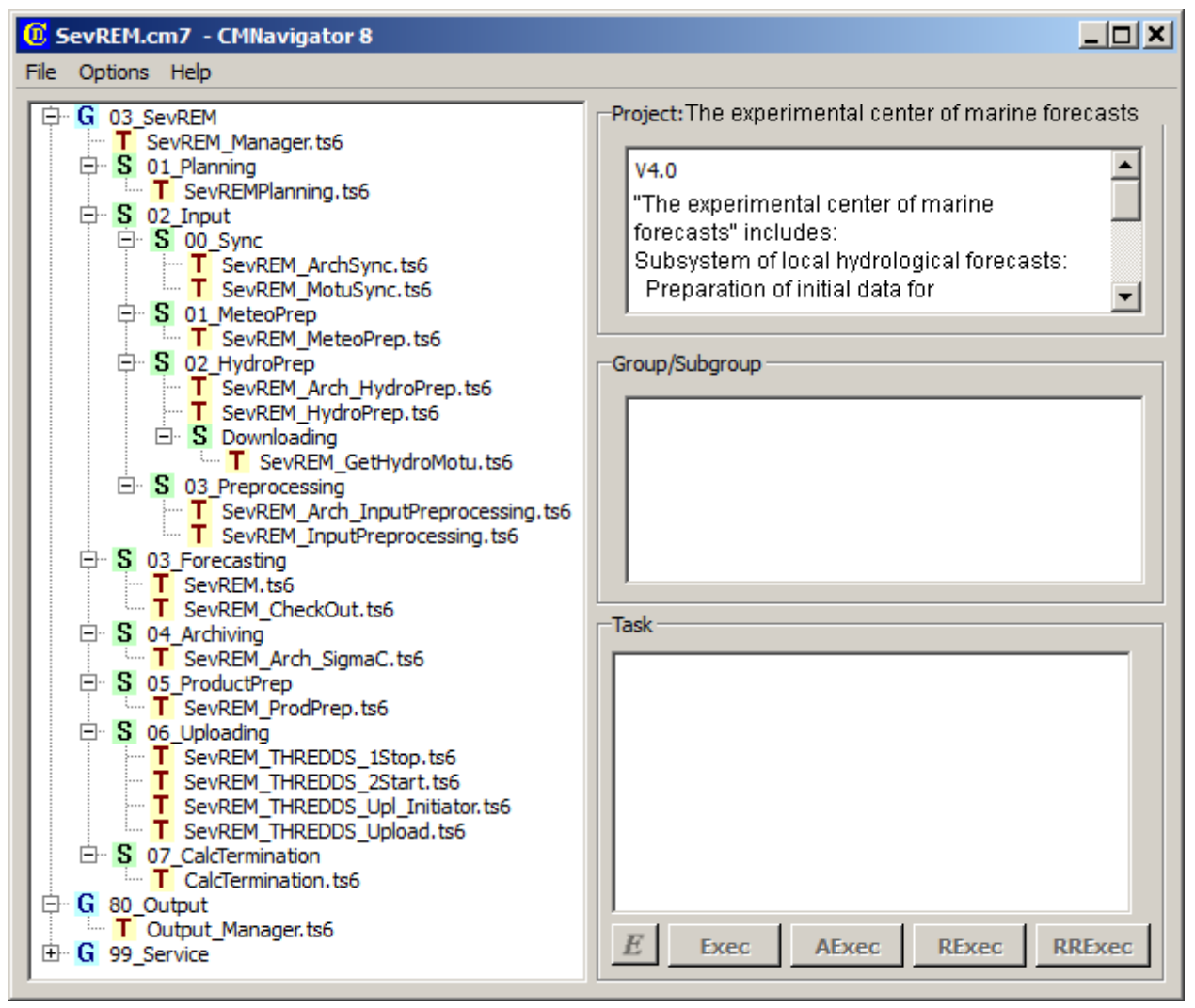

Fig. 1. The system to control the computing process of the local hydrological forecast of the environment parameters' state in the Sevastopol region of the Black Sea

The subsystems include the following tasks which provide direct realization of the operations managing the system functioning: making of directories required for 
the system functioning, copying, file deleting, programs start, analysis of the program completion codes and taking decisions on the tasks completion codes.

The task-manager SevREM_Manager.ts6 controls the system operation in a cycle mode, i. e. starts the necessary tasks, analyzes the results of their operation, makes records on executing these tasks for each operation cycle.

Each cycle of the system automatic functioning consists of the following operations:

- planning of a current simulation cycle, start of a task executing SevREMPlanning.ts6;

- synchronization of start of the input data preparation and readiness of the basin forecast hydrological data which can be done in two ways depending on configuration of a current simulation cycle: either through the local file archive by the SevREM_ArchSync.ts6 task, or through the MOTU interface by the SevREM_MotuSync.ts6 task;

- downloading of the atmospheric forcing data, start of the SevREM_MeteoPrep.ts6 task;

- downloading of the initial and boundary hydrological conditions for the Se$v R E M$ model can also be done in two ways depending on configuration of the current simulation cycle: the data can be obtained from the locale file archive of the basin model output by the SevREM_Arch_HydroPrep.ts6 task or from the THREDDS-server through the MOTU interface by the SevREM_HydroPrep.ts6 task;

- compilation of the input data for entering the model: either the Se$v R E M \_A r c h \_I n p u t P r e p r o c e s s i n g . t s 6$ task (if the local file archive data are used) or the SevREM_InputPreprocessing.ts6 task;

- model calculation, start of the SevREM.ts6 task;

- formal verification of the model output data, start of the SevREM_CheckOut.ts6 task;

- archiving of the model output in a file archive, start of the Se$v R E M \_$Arch_SigmaC.ts6 job task;

- production of the NetCDF-files of a product, start of the SevREM_ProdPrep.ts6 task;

- initiation of downloading the product NetCDF-files on the THREDDSserver, start of the SevREM_THREDDS_Upl_Initiator.ts6 task; task;

- preparation of the next simulation cycle, start of the CalcTermination.ts6

- transition to the next cycle of operation.

By the end of each cycle operation, the results of each task are analyzed and in a case of fatal problems the decision on the SevREM_Manager.ts6 task crash is taken.

\section{Subsystem for visualizing and disseminating the results of the Sevastopol coastal area forecast in the Black Sea}

The subsystem of visualization and dissemination of the results of simulating the marine environment state of the Sevastopol region in the Black operates based on the THREDDS-server [15]. This server is installed, tuned and runs in an operational mode in Marine hydrophysical institute, RAS. Its address in the Internet is http://mis.bsmfc.net:8080/thredds/catalog.html. A set of available products is shown in Fig. 2, $a$.

The results obtained both by the basin models of the Black Sea state monitoring and the local one for the Sevastopol region are placed on this server. The data from the latter are accessible through the SEVREM_ANALYSIS_FORECAST_PHYS_010 product 
The results of the marine environment forecasting system of the Sevastopol region in the Black Sea are visualized through the Godiva2 interface which is a standard component of the THREDDS-server. It permits to obtain the value of the forecasted parameter in any point of the water area, visualize horizontal and vertical cross-sections, create animated images in the preset time intervals and construct time series and vertical profiles. Description of possibilities and examples of application of the interface are given below.

It was already said that it was possible to visualize the following variables: sea level, temperature, salinity, zonal components of current velocities, meridian components of current velocities, currents' vector field. The parameter of interest is selected by clicking a mouse in the upper left corner of the browser, and the field of interest is displayed. The example of visualization is shown in Fig. 4.

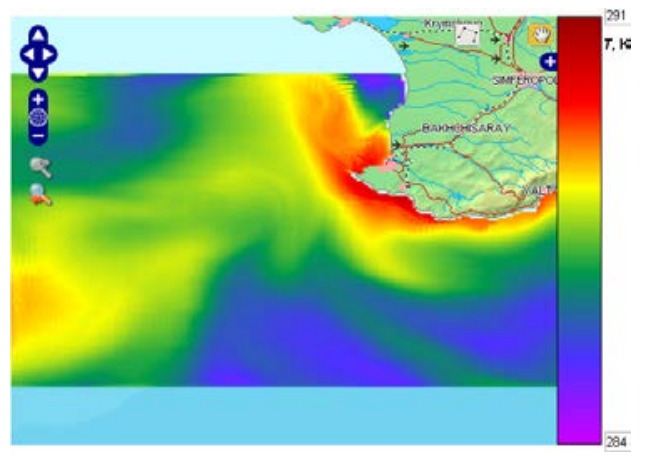

$a$

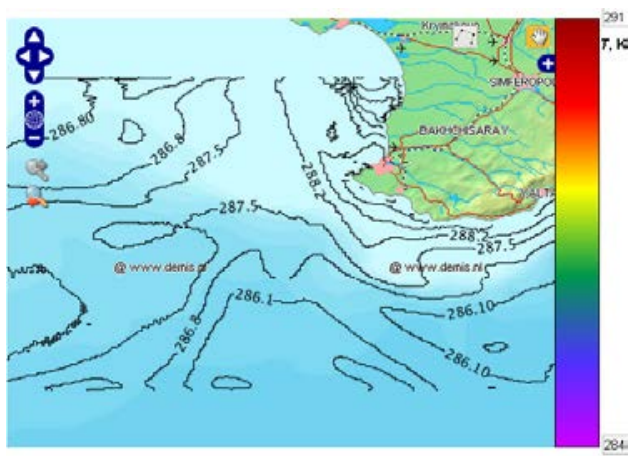

$b$

Pис. 4. Example of visualizing the results of marine environment state nowcasting and forecasting in the Sevastopol region of the Black Sea by solid color $(a)$ and in a form of contours $(b)$

The Godiva2 interface permits to analyze the data of the sea state nowcasting and forecasting in the Sevastopol region, namely:

- to create animated images (Fig. 5). For the purpose of displaying, one has to click the corresponding date in the calendar, select the first and the last frames and fix them by the buttons first frame and last frame. After that the button for starting animation - Create animation - will be accessible; having clicked on it one has to select time resolution for animation. Animation is stopped by pressing the button Stop animation; 


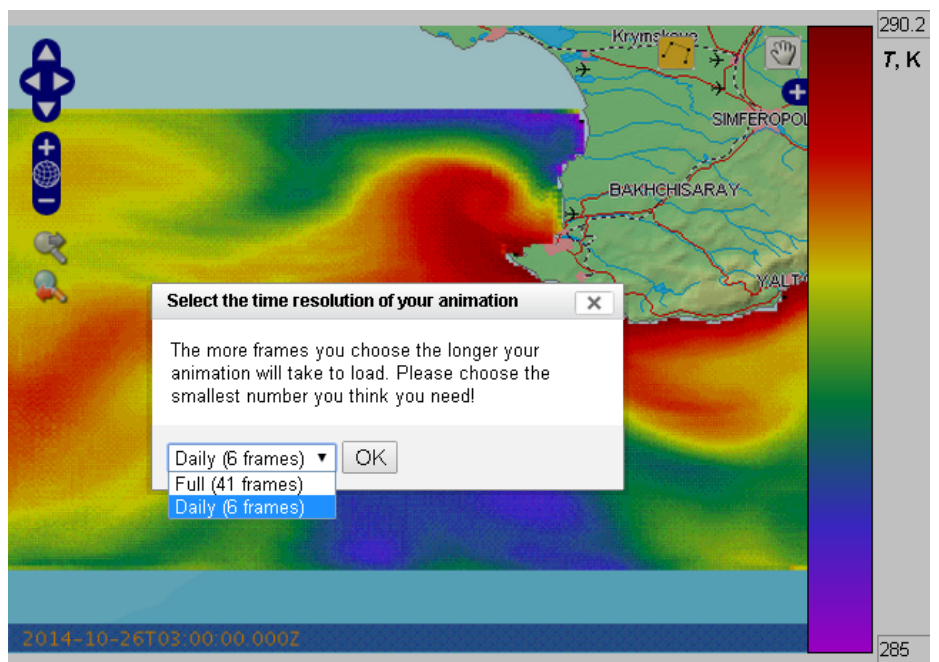

Fig. 5. Example of creating animated images

- to construct time series (Fig. 6). After the first and last frames are preset there appears an opportunity to analyze time series by clicking the mouse left button in the point of interest in the Sevastopol water area and select Create time series plot from menu;

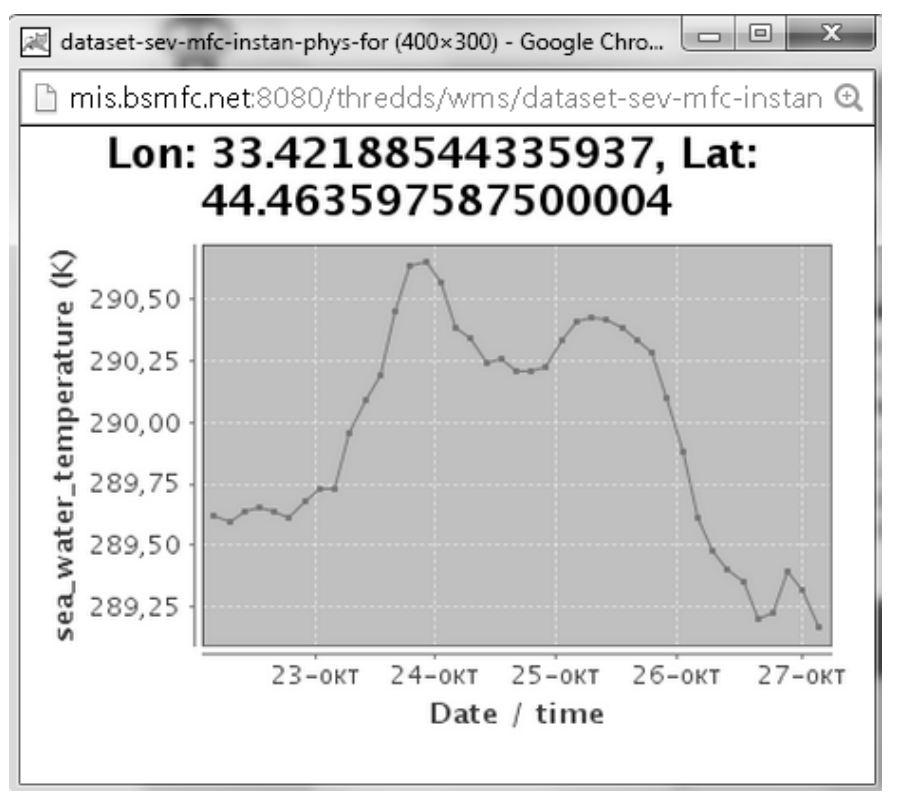

Fig. 6. Example of visualizing time series

- to construct vertical profiles of the selected point (Fig. 7). Click of the mouse left button on the point of interest in the Sevastopol water area also permits to construct and analyze vertical profiles of the selected parameter; 


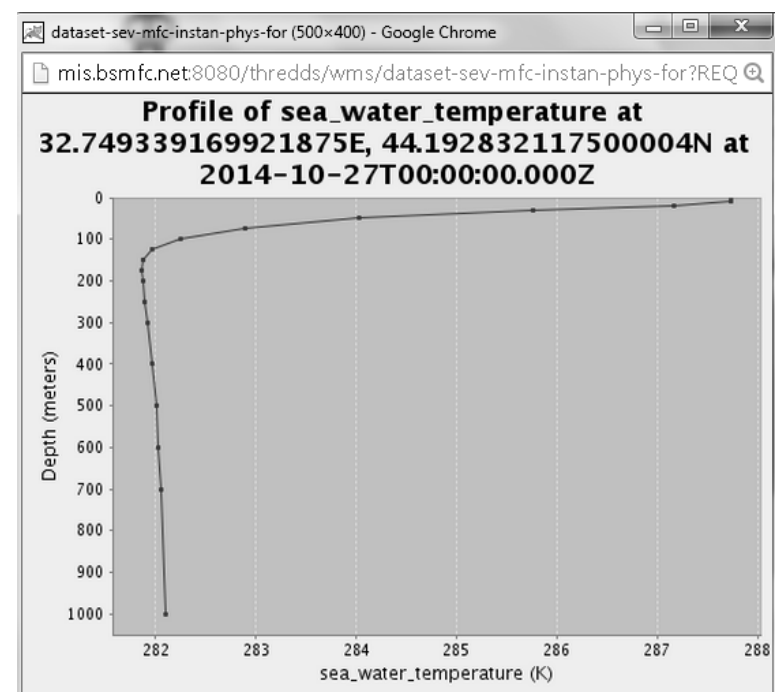

Fig. 7. Example of visualizing a vertical profile

- to construct vertical and horizontal cross-sections (Fig. 8). For this purpose, in the upper right corner one has to select a hologram with a curve; then through the points that are of interest to a user mark the sections on the chart by the abovementioned curve. As a result, the time series along the constructed section and the very vertical section are displayed.

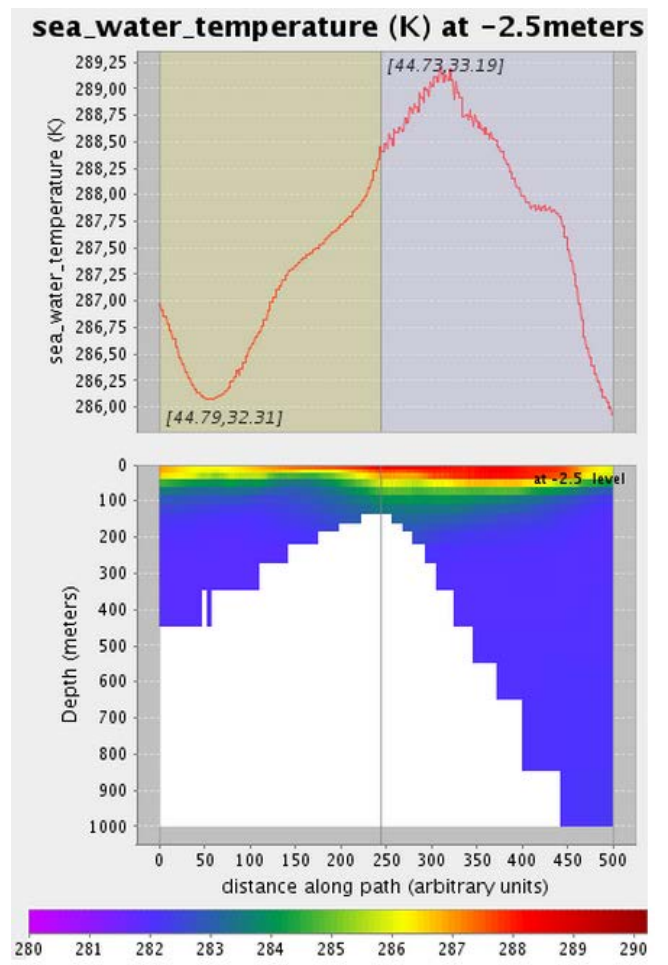

Fig. 8. Example of visualization of a vertical cross-section

PHYSICAL OCEANOGRAPHY NO. 4 (2015) 
Thus, the proposed THREDDS-server possesses all the required instruments for visualization, analysis and dissemination of the results of simulating hydrological parameters of the marine environment state in the Sevastopol region of the Black Sea.

\section{Conclusion}

The automatic system under consideration is developed within the framework of the project RFFR № 14-45-01552. Due to the POM model it performs a continuous nowcasting and forecasting of the marine environment hydrological parameters of the Sevastopol region in the Black Sea. The output fields are available with spatial resolution $1 \mathrm{~km}$ and temporal resolution 3 hours. The system is running in the operational mode from January 20, 2015 and performs simulations in a real time mode. The data are updated daily. No failures have been revealed in the system functioning. The period of a simulation cycle in the operational mode including unloading on the THREDDS-server constitutes 26 minutes. The results of nowcasing and forecasting of hydrological parameters in the Sevastopol region of the Black Sea region are available to users for their visualization, analysis and downloading in the digital form through Internet; the address is http://mis.bsmfc.net:8080/thredds/sevrem-anafor -phys-010.html.

In future it is planned to develop the tools for assessing accuracy of nowcasing and forecasting hydrological fields in the Sevastopol region of the Black Sea and to tune the model for improving accuracy of the forecasted parameters of the marine environment.

\section{REFERENCES}

1. Zavatarelli, M., Pinardi, N., 2003, “The Adriatic Sea modelling system: a nested approach”, Annal. Geophys., vol. 21, no. 1, pp. 345-364.

2. Korres, G., Lascaratos, A., 2003, “A one-way nested eddy resolving model of the Aegean and Levantine basins: implementation and climatological runs”, Annal. Geophys., pp. 205-220.

3. Brenner, S., 2002, "Simulations with a relocatable, nested, high resolution model: the eastern Levantine experience”, Turkey, Ankara: Second International Conference on the Oceanography of the Eastern Mediterranean and Black Sea: Similarities and Differences of Two Interconnected Basins, 7 p.

4. Brenner, S., 2003, "High-resolution nested model simulations of the climatological circulation in the southeastern Mediterranean Sea”, Annal. Geophys., vol. 21, no. 1., pp. 267-280.

5. Tsanis, I.K., Wu, J., 1995, "A nested-grid hydrodynamic/pollutant transport model for nearshore areas in Hamilton Harbour”, Water Qual. Res. J. Can., vol. 30, no. 2, pp. 205-229.

6. Zodiatis, G., Lardner, R. \& Lascaratos, A. [et al.], 2003, "High resolution nested model for the Cyprus, NE Levantine Basin, eastern Mediterranean Sea: implementation and climatological runs”, Annal. Geophys., vol. 21, no. 1, pp. 221-236.

7. Kubryakov, A.I., 2004, "Primenenie tekhnologii vlozhennykh setok pri sozdanii sisyemy monitoringa gidrofizicheskikh poley $v$ pribrezhnykh rayonakh Chernogo morya [Application of the nested grid technology at developing the system of the hydrophysical fields monitoring in the Black Sea coastal regions]", Ekologicheskaya bezopasnost' pribrezhnoy i shelfovoy zon $i$ kompleksnoe ispol'zovanie resursov shelfa, vol. 11, pp. 31-50 (in Russian). 
8. Korotaev, G.K., Kubryakov, A.I. \& Bayankina, T.M. [et al.], 2013, “Itogi razvitiya eksperimentalnogo tsentra morskikh prognozov MGI NAN Ukrainy v $2011-2013$ gg. [Results of development of the marine forecasts experimental center of MHI NAS of Ukraine in 20112013, Ekologicheskaya bezopasnost' pribrezhnoy i shelfovoy zon i kompleksnoe ispol'zovanie resursov shelfa, vol. 27, pp. 134-138 (in Russian).

9. Vandenbulcke, L., Barth, A. \& Alvera-Azcarate, A. [et al.], 2004, “A nested-grid model with data assimilation in the Gulf of Lions”, Geophys. Res. Abstr., vol. 6, p. 01989.

10. Mikhailova, E.N., Shapiro, N.B., 1996, "Modelirovanie rasprostraneniya i transformatsii rechnykh vod na severo-zapadnom shelfe i v glubokovodnoy chasti Chernogo morya [Modeling of the river waters propagation and transformation on the north-western shelf and in the deep-water part of the Black Sea]", Morskoy gidrofizicheskiy zhupnal, vol. 3, pp. 30-40 (in Russian).

11. Ginis, I., Richardson, R.A. \& Rothstein, L.M., 1998, "Design of a multiply nested primitive equation ocean model”, Mon. Wea. Rev., vol. 126, no. 4, pp. 1054-1079.

12. Martin, P.J., 2000, "Description of the Navy Coastal Ocean Model Version 1.0", Naval Research Laboratory Technical Report; NRL/FR/7322-00-9962, 45 p.

13. Ivanchik, A.M., Ivanchik, M.V., 2012, “Kompyuternaya programma "CalcMan” - kompleks program dlya upravleniya protsessom vychisleniy [Software "CalcMan is a program complex for managing the calculation process]”, Svidetelstvo № 46521 o registratsii avtorskogo prava na kompyuternuyu programmu, 1 p. (in Russian).

14. Ivanchik, A.M., Ivanchik, M.V., 2012, "Kompyuternaya programma "CalcManPack" - komandny yazyk paketa dlya upravleniya protsessom vychisleniy, prednaznachenny dlya razrabotki $i$ vypolneniya zadaniy, kotorye upravlyayut informatsionno-vychiclitelnymi protsessami [Software "CalcManPack" is a package language for managing the calculation process, intended for developing and fulfilling the tasks that control the information-computational processes]”, Svidetelstvo № 46522 o registratsii avtorskogo prava na kompyuternuyu programmu, 1 p. (in Russian).

15. http://www.unidata.ucar.edu/downloads/thredds/index.jsp. 